I CONFERÊNCIA SOBRE AS

COMUNIDADES BRASILEIRAS

NO EXTERIOR

BRASILEIROS NO MUNDO 


\section{MINISTÉRIO DAS RELAÇÕES EXTERIORES}

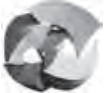

$\begin{array}{ll}\text { Ministro de Estado } & \text { Embaixador Celso Amorim } \\ \text { Secretário-Geral } & \text { Embaixador Samuel Pinheiro Guimarães }\end{array}$

Secretaria-Geral das

Comunidades Brasileiras

no Exterior

Embaixador Oto Maia

FUNDAÇÃO ALEXANDRE DE GUSMÃO

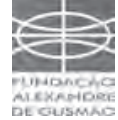

Presidente
Embaixador Jeronimo Moscardo

Instituto de Pesquisa de

Relações Internacionais

Diretor
Embaixador Carlos Henrique Cardim

A Fundação Alexandre de Gusmão, instituída em 1971, é uma fundação pública vinculada ao Ministério das Relações Exteriores e tem a finalidade de levar à sociedade civil informações sobre a realidade internacional e sobre aspectos da pauta diplomática brasileira. Sua missão é promover a sensibilização da opinião pública nacional para os temas de relações internacionais e para a política externa brasileira.

Ministério das Relações Exteriores Esplanada dos Ministérios, Bloco $\mathrm{H}$

Anexo II, Térreo, Sala 1

70170-900 Brasília, DF

Telefones: (61) 3411-6033/6034

Fax: (61) 3411-9125

Site: www.funag.gov.br 


\section{Conferência sobre as Comunidades Brasileiras no Exterior}

\section{Brasileiros no Mundo}

Rio de Janeiro, 17 e 18 de julho de 2008

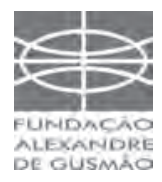

Brasília, 2009 
Direitos de publicação reservados à

Fundação Alexandre de Gusmão

Ministério das Relações Exteriores

Esplanada dos Ministérios, Bloco H

Anexo II, Térreo

70170-900 Brasília - DF

Telefones: (61) $34116033 / 6034$

Fax: (61) 34119125

Site: www.funag.gov.br

E-mail: funag@mre.gov.br

Capa:

Adriano Motta

\section{Equipe Técnica}

Coordenação:

Eliane Miranda Paiva

Maria Marta Cezar Lopes

Cíntia Rejane Sousa Araújo Gonçalves

Erika Silva Nascimento

Programação Visual e Diagramação:

Juliana Orem e Maria Loureiro

Impresso no Brasil 2009

I Conferência "Brasileiros no Mundo" / Textos elaborados por autoridades governamentais, acadêmicos, especialistas e brasileiros residentes no exterior para subsidiar os trabalhos e discussões da I Conferência "Brasileiros no Mundo", realizada no Palácio Itamaraty do Rio de Janeiro em 17 e 18 de julho de 2008, pela Subsecretaria Geral das Comunidades Brasileiras no Exterior (SGEB), do MRE, em parceria com a Fundação Alexandre de Gusmão. - Brasília, 2009. $464 \mathrm{p}$.

ISBN: 978-85-7631-162-1

1. Migração - Brasil. I. Ministério das Relações Exteriores. Subsecretaria Geral das Comunidades Brasileiras no Exterior. II. Fundação Alexandre de Gusmão.

CDU 314.15(81)

Depósito Legal na Fundação Biblioteca Nacional conforme Lei $\mathrm{n}^{\circ} 10.994$, de 14/12/2004. 


\section{Sumário}

Fotos do Evento, 9

Apresentação, 17

Discurso de Abertura, 19

Ministro Celso Amorim

1. Brasileiros no Mundo: $\mathrm{O}$ ambiente mundial das migrações e a ação governamental brasileira de assistência a seus nacionais no exterior, 25

Oto Agripino Maia

2. Uma Política Governamental para as Comunidades Brasileiras no Exterior, 47 Eduardo Gradilone

3. Exame Comparado de Políticas para Comunidades Nacionais no Exterior, 81 George Torquato Firmeza

4. A Eleição de Representantes de Brasileiros no Exterior para o Congresso Nacional, 105

Carlos Eduardo de Ribas Guedes

5. Atuação Governamental em Relação às Comunidades Brasileiras no Exterior na área de Previdência - Acordos Internacionais de Previdência Social, 147 Helmut Schwarzer

6. Atuação Governamental em Relação às Comunidades Brasileiras no Exterior na área trabalhista, 155

Paulo Sérgio de Almeida 
7. Notas sobre a Questão Educacional das Comunidades de Brasileiros no Exterior. A Atuação Governamental e seus Desafios, 173

Cesar Callegari

8. Governabilidade das migrações internacionais e direitos humanos: o Brasil como país de emigração, 187

Neide Lopes Patarra

9. Migração internacional, dinâmica demográfica e desafios para o dimensionamento da comunidade brasileira no exterior, 213

Juarez de Castro Oliveira

10. Controles Migratórios. Inadmitidos: o que fazer? Opções para as pessoas e para os Estados, 241

André Regis

11. Migração e Redes Sociais: a distribuição de brasileiros em outros países e suas estratégias de entrada e permanência, 259

Wilson Fusco

12. Remessas de Brasileiros no Exterior, 279

Luciano Schweizer

13. Imprensa Comunitária Brasileira no Exterior, sobretudo nos EUA: uma abordagem histórica, estatística e referencial daquilo que se sabe sobre a nossa presença, 299

Carlos Borges, Edilberto Mendes e Roberto Lima

14. Cidadãs e Cidadãos Brasileiros no Exterior - O Documento de Lisboa, a Carta de Boston e Documentos de Bruxelas, 317

Rosita Milesi e Orlando Fantazini

15. Entidades de União e de Apoio a Brasileiros e Brasileiras no Exterior, 333 Carmem Lussi

16. Brasileiros na América do Sul, 363

Rosana Baeninger

17. Brasileiros nos Estados Unidos, 383

Teresa Sales 
18. Os Brasileiros na Europa: notas introdutórias, 399

Duval Magalhães Fernandes e José Irineu Rangel Rigotti

19. Brasileiros no Japão, 427

Elisa Massae Sasaki

20. A Gestão Migratória e o Paradoxo da Grandeza, 447

Eduardo L. G. Rios-Neto e Ernesto F. Amaral 


\title{
A Gestão Migratória e o Paradoxo da Grandeza
}

\author{
Eduardo L. G. Rios-Neto* \\ Ernesto F. Amaral ${ }^{* *}$
}

\section{Introdução}

Este trabalho analisa as perspectivas de gestão migratória no Brasil à luz do paradoxo da grandeza. Na introdução são mencionados, resumidamente, os fatos migratórios brasileiros. Em seguida, são analisadas algumas tendências e mudanças no cenário internacional de migração. Em terceiro lugar, o conceito de gestão migratória é discutido no contexto brasileiro. Em seguida, é introduzido o paradoxo da grandeza, apresentado como um possível obstáculo para a realização de uma boa gestão migratória, e são mencionados, também avanços que podem diminuir a força do paradoxo da grandeza. Em quinto lugar, é mencionado o caso mexicano de gestão migratória como um exemplo de melhor prática. Finalmente, a conclusão reflete sobre as perspectivas de gestão migratória no caso brasileiro.

Um breve sumário da literatura disponível, sem citações detalhadas, mostra os seguintes aspectos relativos ao saldo migratório e outras dimensões sobre a migração internacional brasileira:

1. O Brasil foi país receptor de população, final do século XIX até os dois primeiros quintos do $\mathrm{XX}$.

\footnotetext{
* Professor Titular no Departamento de Demografia e Cedeplar/ UFMG, Presidente da CNPD - Comissão Nacional de População e Desenvolvimento.

** Pesquisador no Cedeplar/UFMG - FAPEMIG.
} 
2. O Brasil teve população "fechada" entre o pós-guerra e os anos 70 do século passado.

3. A partir do ano de 80 , o saldo migratório líquido se tornou negativode 1,8 milhões de pessoas.

4. Na década dos 90 do século anterior, o saldo foi negativo de 550 mil pessoas (cálculo de José Alberto Magno de Carvalho), arrefecendo o processo.

5. A partir de 2000, há uma grande dúvida sobre o tamanho do saldo, o qual provavelmente aumentou no último qüinqüênio e pode estar diminuindo na segunda metade de novo, por causa do controle mais duro do fluxo.

6. Parece haver um estoque significativo de brasileiros vivendo no exterior: a estimativa mínima é de 1 milhão de brasileiros, sendo mais plausível algo como 1,9 milhões de brasileiros; antes do retorno mais recente dos últimos anos, há referências exageradas mencionando até 2,5 vezes este valor.

Mesmo com o saldo migratório negativo, ou seja, com o fluxo emigratório maior do que o fluxo imigratório, o Brasil continua sendo também um país receptor de imigrantes. Neste sentido, qualquer tentativa de regulação migratória por parte do governo deve contemplar tanto a emigração quanto a imigração.

Sob o ponto de vista da imigração, o fluxo imigratório deve distinguir entre o fluxo de migração documentada para o trabalho, regulada pela concessão de vistos de trabalho pelo MTE (Ministério do Trabalho e Emprego). Este fluxo compreende a entrada de estrangeiros de praticamente todos os países. O segundo fluxo refere-se à imigração dos países fronteiriços do País. A imigração de fronteira compreende um segmento documentado que pouco se distingue da categoria anterior, mas também inclui a migração irregular, principalmente aquela vinda do Paraguai e da Bolívia.

Já a emigração de brasileiros deve ser separada em quatro grandes fluxos, que se distinguem quanto à documentação, inserção no mercado de trabalho e nível de seletividade ("brain drain"). O primeiro fluxo compreende a emigração de brasileiros para os países de fronteira na América Latina. $\mathrm{O}$ segundo fluxo compreende a emigração para a América do Norte, principalmente para os Estados Unidos, e, em menor proporção, para o Canadá. O terceiro fluxo compreende a emigração de brasileiros (dekaseguis) para o Japão. O quarto fluxo compreende a emigração para os países da Europa. Com base nos fluxos acima citados, é possível sugerir uma distinção 
tipológica entre emigrações intracontinentais (predominantemente fronteiriças) de brasileiros e emigrações intercontinentais (totalmente não-fronteiriças) de brasileiros.

\section{Tendências e mudanças na migração internacional}

A migração internacional vem sofrendo mudanças recentes, com destaque para alguns aspectos, como a redução do fluxo irregular de migração de trabalho, o aumento da demanda global por mão-de-obra qualificada, com ênfase para o debate sobre brain drain nos países de origem, a importância da migração diaspórica, o papel das remessas associado à emigração, o ciclo das conferências e convenções internacionais com o multilateralismo, e, finalmente, a relação entre migração e direitos humanos.

\section{A migração irregular e tendências futuras para a migração de trabalho}

Há várias possibilidades para que um indivíduo seja considerado um migrante com condição ou status irregular. Qualquer que seja o motivo, alguns países desenvolvidos vêm tentando reduzir este fluxo sob o argumento de defesa da soberania e segurança nacional. Por outro lado, há uma série de razões que explicam a crescente demanda pelo trabalho do imigrante internacional nos países desenvolvidos, incluindo aquele fluxo de imigrantes com baixa qualificação. Entre estas razões, destaca-se a crescente globalização da economia, o envelhecimento populacional nos países desenvolvidos, que gera uma demanda por força de trabalho mais jovem, e a segmentação do mercado de trabalho urbano nestes países, onde os nativos se recusam a aceitar trabalho em alguns tipos de ocupações.

Sendo assim, a combinação, no mesmo país desenvolvido, entre um controle cada vez maior no fluxo de entrada de estrangeiros adicionado pelo foco na expulsão de imigrantes irregulares e a crescente demanda por trabalho estrangeiro, causa, ao mesmo tempo, uma maior demanda por programas de migração permanente e temporária de trabalho nestes países. Estes programas de migração temporária para o trabalho estão longe de ser bem sucedidos, como mostra a avaliação histórica do "guest work program Bracero", a respeito da migração temporária de mexicanos para os Estados Unidos. No contexto do maior "endurecimento" na entrada e permanência de imigrantes irregulares 
nos países desenvolvidos, parece ser no melhor interesse dos cidadãos nacionais dos países de origem que estes façam acordos bilaterais entre países, assim como regulem as ações do setor privado, para não prejudicar os direitos de seus nacionais. Claramente, o programa de migração temporária pode não ser considerado o ideal (um caso de "second best"), mas certamente é melhor para o país de origem do que ter seus nacionais em situação totalmente irregular, se sujeitando a violações de direitos sociais básicos e humanos.

\section{A demanda global por talentos e o Brain-Drain}

O debate sobre dreno ou fuga de cérebros é antigo na literatura que trata da relação entre migração e desenvolvimento econômico. Tradicionalmente, países sul-asiáticos, como a Índia, forneciam trabalho altamente qualificado para os países desenvolvidos; mais recentemente, a globalização amplificou a demanda por trabalho altamente qualificado no mundo. Esta demanda muitas vezes se localiza em profissionais de determinadas áreas, como é o caso dos profissionais da saúde (médicos e enfermeiros), que têm abandonado países no continente africano e na Ásia. A demanda global por MBAs é outro exemplo nessa linha. Mais recentemente, o boom de demanda por matérias-primas minerais tem elevado a demanda global por profissionais nas engenharias associadas a esta área. Atualmente, o conceito de braindrain tem uma conotação mais crítica do que tinha no passado, implicando uma demanda por compensações por parte de países mais pobres. Os países desenvolvidos têm adaptado o termo para minimizar seus aspectos negativos, denominando o fenômeno como "circulação de talentos".

Independentemente da questão das perdas para as sociedades que formaram estes profissionais, a questão é que a maior demanda por trabalho qualificado em escala global pode, nos tempos atuais, ser um gargalo ou estrangulamento para o desenvolvimento local. Hoje é possível pensar que o Brasil venha a perder profissionais qualificados para as economias desenvolvidas, por conta da globalização, e, ao mesmo tempo, venha recorrer a profissionais qualificados de países vizinhos (migração intracontinental qualificada) ou mesmo de outros países em desenvolvimento. ${ }^{1}$

\footnotetext{
${ }^{1}$ Certamente o futebol é um exemplo nesta direção. Há um brain drain de craques brasileiros para a Europa, enquanto o campeonato brasileiro está gerando uma demanda por craques de outros países latino-americanos.
} 
A literatura sobre brain-drain falava de 3 Rs (recrutamento, remessas e retorno). Outros Rs se adicionam ao debate contemporâneo. Retenção é um deles; é claro que para um país que investiu em educação superiore pós-graduação, o ideal seria reter seu profissional no país. No caso da impossibilidade de retenção, argumenta-se que pode haver um efeito indireto na expansão da graduação em ensino superior, como decorrência do aumento da taxa de retorno para educação; este argumento não tem sido muito comprovado. Uma alternativa levantada seria a possibilidade de um retorno, com prazo definido, da saída destes profissionais. Neste caso, o retorno pode justificar a saída, desde que o período no exterior represente algum aprendizado. Há controvérsias sobre as vicissitudes deste retorno, mas há também referências sobre redes formais e informais de pesquisas e absorção de tecnologias decorrentes deste tipo de migração.

\section{A migração diaspórica}

Uma diáspora relaciona-se com a organização social das comunidades de origem nos países de destino, sem ruptura de laços com os países de naturalidade, ou seja, mantendo uma certa identidade nacional. Adiáspora funciona como uma verdadeira rede social, tendo gerado vários aspectos positivos no contexto internacional. Muitas destas diásporas têm contribuído para a defesa dos direitos humanos dos migrantes, e outras têm contribuído para o desenvolvimento comunitário nas regiões de origem, como é o caso da remessa para fundos comunitários mexicanos. Um ponto central na migração diaspóricaé sua oposição à completa assimilação cultural, no sentido proposto pelas teorias sociológicas funcionalistas. Isto significa que os migrantes não pretendem abandonar suas origens, mesmo que num contexto simbólico. A migração internacional brasileira apresenta sinais diaspóricos, pelo menos no caso dos brasileiros nos EUA, dos dekaseguis, dos brasileiros em Portugal, na Espanha e, até mesmo, com bastante intensidade, dos brasiguaios no Paraguai. Exatamente por ser diferente da assimilação cultural funcionalista ou pura, a migração diaspórica vem sofrendo crescente xenofobia no mundo. Este é um fato novo importante para o contexto da gestão migratória a ser discutida posteriormente neste trabalho.

\section{Remessas}

As remessas dos migrantes, "descobertas" pela comunidade financeira internacional, vêm-se expandindo recentemente e constituem-se em importante 
nicho para as instituições financeiras internacionais. Um ponto importante refere-se ao papel das remessas no desenvolvimento das comunidades locais e dos países de origem. O papel das remessas nas políticas públicas e de desenvolvimento dos países de origem vem sendo deturpado. As remessas são de nível micro e de propriedade familiar; portanto, a maioria das vezes elas têm o intuito exclusivo de cobrir necessidades de consumo familiar. Sendo assim, sob o ponto de vista micro, o uso final dos recursos enviados (consumo e investimento) deve ser soberano e privado, não cabendo a nenhum estado intervir na sua destinação.

De qualquer maneira, a remessa, sob uma perspectiva macroeconômica, é benéfica aos países de origem dos migrantes, pelo fato de gerar divisas internacionais. Neste sentido, as remessas agem como se fossem receitas de exportações. Alguns países têm as remessas dos migrantes como a maior fonte de divisas. Mesmo no caso do Brasil, com a pauta de exportação diversificada que possui, não é possível considerar que as divisas geradas pelas remessas sejam desprezíveis.

Uma política de remessas aceitável é a redução dos custos financeiros da transferência internacional dos recursos. Até recentemente, no Brasil, e ainda hoje em muitos países, estes custos são bastante elevados, e não há justificativa para o alto valor das taxas cobradas. Há evidências de associações comunitárias congregando migrantes de uma mesma cidade de origem vivendo na mesma vizinhança de um país de destino. No caso mexicano, as home town associations criam fundos para apoiar o investimento em seus municípios, e há exemplos de políticas públicas onde, para cada dólar enviado pela associação para um certo programa de desenvolvimento, os governos local e nacional adicionam 2 ou 3 dólares, conforme será destacado no exemplo de melhores práticas. Esforços desta natureza devem ser vistos positivamente, desde que sejam de natureza voluntária e não alterem os direitos dos migrantes na determinação do destino final de seus recursos.

\section{O ciclo de Conferências Internacionais}

O Secretário Geral das Nações Unidas encomendou um relatório especial para discutir as linhas gerais sobre migração internacional. Sendo assim, a Global Commission on International Migration (GCIM) foi criada, em 2003, para elaborar um relatório no contexto do multilateralismo. O relatório trata de várias dimensões da migração internacional, com ênfase nos direitos 
humanos dos migrantes, mas também enfatizando a importância da gestão migratória. O documento da GCIM serviu de base para a agenda do Encontro de Alto Nível das Nações Unidas, que se realizou na ONU, em setembro de 2006. A Reunião de Alto Nível criou um "Fórum Global em Migração em Desenvolvimento", que passou a ser um fórum de países, ao invés de um fórum multilateral, tendo ocorrido na Bélgica em 2007 e nas Filipinas em 2008.

Um fator importante determinando esta transição é a relutância dos países desenvolvidos em discutir questões migratórias que poderiam afetar sua soberania nacional, quando discutidas em fóruns multilaterais, onde os interesses de países com perfil típico de emigração podem prevalecer. Um exemplo é a "Convenção Internacional sobre a Proteção dos Direitos de Todos os Migrantes Trabalhadores e Membros de sua Família", uma resolução adotada pela Assembléia Geral das Nações Unidas em 1990, mas ratificadas apenas por países que estão na condição de região de origem do fluxo internacional migratório. Esta convenção é uma das peças mais avançadas na defesa dos direitos humanos dos migrantes, mas não foi ratificada pela maioria dos países desenvolvidos. Há uma resistência dos países desenvolvidos em aceitar as garantias de direito sugeridas na convenção, particularmente no caso dos migrantes residindo em condições irregulares nos países de destino. Este processo é acompanhado por uma repressão cada vez maior à imigração irregular (não-documentada) nos países desenvolvidos, com um sentimento de xenofobia cada vez maior. Esta resistência dos países desenvolvidos aos imigrantes é menos devido a fatores econômicos e mais relacionada com crescente xenofobia e com conflitos culturais e étnicos. Neste contexto, a não-divisibilidade dos direitos humanos entra em conflito com os alegados direitos de soberania dos países desenvolvidos. Alguns países estão cada vez mais restritos na provisão até de direitos sociais básicos para os migrantes não-documentados e seus familiares. Um conflito importante na questão migratória coloca os direitos humanos de um lado, em contraposição a argumentações de segurança nacional. A ligação da migração internacional com o terrorismo internacional e o tráfico de drogas têm contribuído para o aumento da xenofobia. Claramente, há também um conflito nas tentativas de governabilidade da migração internacional, onde as entidades supranacionais tentam ampliar seu escopo de atuação, com o 
apoio da sociedade civil organizada, e os governos buscam preservar sua soberania nesta área. Este contexto reforça a importância de se ficar cada vez mais atento à tendência de formalização do fluxo migratório, inclusive com crescente utilização de programas formais de migração temporária.

\section{A Gestão Migratória no Contexto Brasileiro}

A Figura 1 abaixo apresenta o contexto atual da regulação migratória no Brasil. Esta regulação compreende atividades relacionadas com três ministérios: Ministério da Justiça, Ministério das Relações Exteriores e Ministério do Trabalho e Emprego.

\section{Figura 1 - Os Principais Reguladores da Migração Internacional no Brasil}
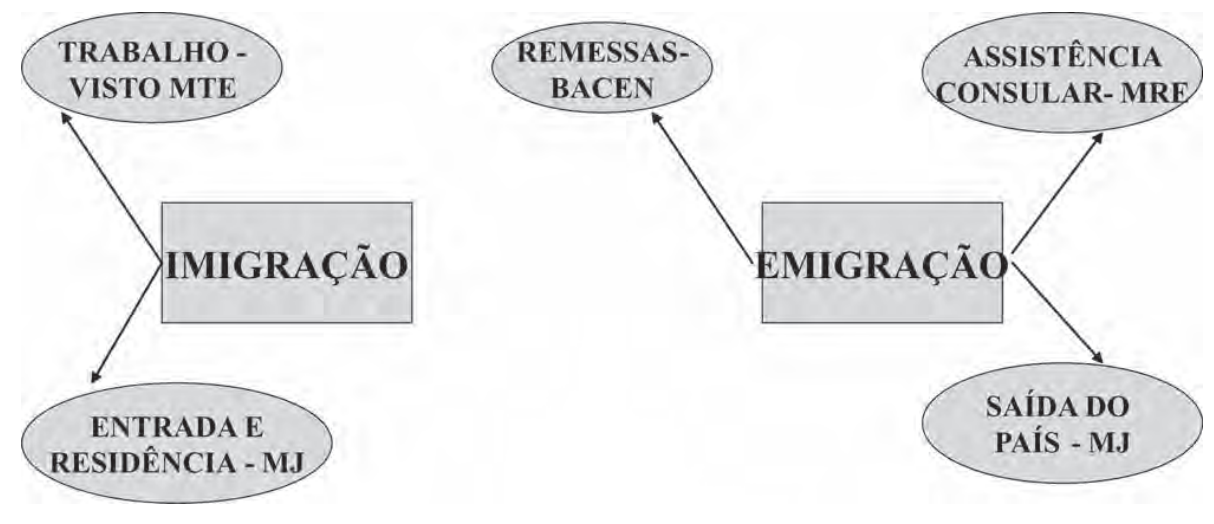

Uma coordenação integrada (concertação) da política de gestão migratória demandaria uma maior articulação entre pelo menos estes três ministérios. Atualmente, o Conselho Nacional de Imigração (CNIg do Ministério do Trabalho e Emprego - MTE) é o único mecanismo de coordenação (concertação) que integra a participação dos três ministérios, embora funcione num dos ministérios e tenha atribuições de regulação da imigração (estrangeiro residente no Brasil) voltada para o trabalho. 
Mais recentemente, o CNIg vem ampliando seu interesse pela defesa dos direitos dos brasileiros no exterior, tendo elaborado e divulgado a cartilha "Brasileiras e brasileiros no exterior - Informações Úteis", que busca orientar os brasileiros residentes no exterior ou que planejam a emigração, documentada ou não, sobre os riscos e seus direitos no exterior. O CNIg também realizou diligências em uma série de países com presença de brasileiros, como Portugal, Espanha, Estados Unidos da América, Japão e Paraguai. Tais missões serviram para delinear um quadro acerca dos anseios e necessidades de assistência dos brasileiros residentes no exterior. O MTE pretende, através do CNIg, criar a casa do trabalhador brasileiro no exterior. Uma primeira experiência, em território brasileiro, resultou em parceria com a Prefeitura de Foz do Iguaçu, para defender os interesses dos trabalhadores brasileiros no Paraguai.

O Ministério das Relações Exteriores (MRE) já conta com a experiência do "Programa Consulado Itinerante", que busca atender às demandas dos cidadãos brasileiros perto de suas residências e comunidades. O MRE passou por reestruturação mais recente, visando uma melhoria no atendimento consular e à elaboração uma nova estratégia de relacionamento com os brasileiros residentes no exterior. Alguns consulados no exterior exercitaram planos pilotos de matrícula consular, mas tais experimentos careceram de uma avaliação de impacto mais rigorosa no que tange aos benefícios gerados para os brasileiros residentes no exterior.

Vários desafios persistem no que tange à gestão migratória no Brasil. Sob o ponto de vista do marco legal, a "Nova Lei do Estrangeiro" ainda não teve sua redação concluída e foi aprovada no Congresso Nacional. Os últimos rascunhos da lei apontam para importantes avanços na defesa dos direitos humanos no que tange ao estrangeiro residente no país. A lei pode servir de instrumento de pressão para a defesa dos direitos dos brasileiros residentes no exterior, mas a lei não trata desta matéria. Quanto ao brasileiro residente no exterior, o documento de Lisboa, elaborado em 2002, ainda é uma referência. $\mathrm{O}$ documento trata do comprometimento da cidadania brasileira por parte dos brasileiros residentes no exterior, e busca a criação de uma instância interministerial para cuidar da emigração, ou seja, do atendimento e apoio aos emigrantes brasileiros, inclusive com incentivo a seu regresso. $\mathrm{O}$ documento trata também da necessidade de representação política dos emigrantes brasileiros. É sugerida a criação de um "Estatuto do Brasileiro no Exterior", que cuidaria dos direitos e deveres de brasileiros no exterior. $\mathrm{O}$ 
documento demanda explicitamente uma maior atuação das embaixadas nas questões políticas, sociais, jurídicas e econômicas afetas aos emigrantes, e identifica uma demanda por melhorias no atendimento consular. A matrícula consular é citada como demanda sob o nome de inscrição consular, com demanda por informatização dos documentos. A aprovação da "Nova Lei do Estrangeiro" representará importante avanço, mas, a despeito das limitações jurídicas, a elaboração de algo que se assemelhe a um "Estatuto do Brasileiro no Exterior" é imperativo para a viabilização de uma autêntica política de gestão migratória no país.

Alguns exemplos ilustram potenciais positivos para uma maior defesa do brasileiro residente no exterior. Um caso importante foi a atuação do Congresso Nacional, particularmente da Comissão Mista sobre Migração Ilegal. No caso da migração intracontinental, o acordo de residência do Mercosul e sua implementação bilateral, até que o acordo seja ratificado por todos os países, é outro exemplo positivo. A realização de acordos fronteiriços também é bastante positiva. No âmbito do Ministério da Justiça destaca-se a atuação nos tráficos de seres humanos, notadamente no caso de crianças e mulheres.

Se a "Nova Lei do Estrangeiro" fala de uma instância interministerial para o estrangeiro residente no país, esta instância é igualmente necessária no caso do brasileiro residente no exterior. O CNIg e o MRE vêm envidando esforços nesta direção, mas a institucionalização está longe de ser completamente definida. Esta necessidade torna-se mais premente ainda se o diagnóstico de que o combate internacional dos países desenvolvidos crescerá nos próximos anos se confirmar, mesmo que acompanhado por uma persistente demanda por trabalho estrangeiro, devido à maior circulação de talentos, mas também à escassez de mão-de-obra, principalmente nos setores de serviços menos qualificados. É neste contexto que o "Paradoxo da Grandeza", abaixo definido, torna-se extremamente relevante.

\section{O Paradoxo da Grandeza}

O conceito de "grandeza" como parte do futuro que espera o Brasil está presente não só no hino nacional, mas também no regime autoritário, e, no caso da política externa brasileira, em várias fases históricas coincidentes com regimes políticos e ideológicos diferentes. O tema diplomático não é especialidade dos autores, nem é propósito deste trabalho investigar a 
influência da noção de "grandeza" na política externa brasileira ${ }^{2}$. O paradoxo da grandeza neste trabalho é uma figura de retórica, visando a chamar a atenção para um problema relevante para a cidadania brasileira, mas que pode parecer pequeno no contexto das pretensões mais amplas de grandeza da diplomacia brasileira, como é o caso das pretensões de participação no "Conselho de Segurança da Organização das Nações Unidas". A questão da emigração e dos brasileiros residentes no exterior é muito pequena diante dos desafios de um gigante adormecido de futuro grandioso. O paradoxo consiste, precisamente, no gigante adormecido, que, a rolar na cama para acordar, diante de tanta grandeza, prejudica seu filho, que dormia ao seu lado, aspirando a participar do mundo exterior em uma diáspora de brasileiro. Este paradoxo se manifesta de várias formas, no que concerne à questão migratória:

- Na oposição entre multilateralismo e bilateralismo (que favorece os migrantes em acordos bilaterais com países em favor dos brasileiros em situações específicas);

- Na dificuldade para entender as demandas individuais dos brasileiros que aspiram a mobilidade econômica e social na esfera internacional, a despeito do futuro grandioso que o Brasil pode oferecer;

- Na dificuldade em negociar acordos de migração temporária de brasileiros (qualificados ou não-qualificados), por temer que isto afete as aspirações ao Conselho de Segurança Nacional das Nações Unidas ou afete a auto-estima de um país que é potência emergente do século XXI;

- Na dificuldade em entender que o Brasil não é autárquico, de tal forma que num mundo globalizado, onde há circulação de bens e de capital, deve necessariamente haver circulação de pessoas, sendo que a diáspora dos brasileiros é tão positiva quanto a diáspora de outros povos.

A questão do atendimento consular voltado para a comunidade de brasileiros no exterior pode ser vista como algo indiretamente relacionado

\footnotetext{
${ }^{2} \mathrm{O}$ momento clássico de grandeza no período autoritário refere-se ao Governo Médici, período não tão profícuo em termos de política externa, mas parece inegável que figuras ilustres da política externa brasileira, como o Ministro Azeredo da Silveira, em seu pragmatismo responsável, ou mesmo o Ministro Celso Amorim, fizeram uso explícito da noção de grandeza em determinadas circunstâncias. Análise dos discursos dos Presidentes Fernando Henrique Cardoso e Luiz Inácio Lula da Silva em cerimônias de formatura dos novos diplomatas também deixa transparecer a noção de grandeza.
} 
com o paradoxo da grandeza. Isto, porque o corpo diplomático tende a considerar estas questões de cidadania dos estrangeiros como questões menores, de pouco desafio intelectual, em comparação com as questões comerciais e geopolíticas estratégicas. De fato, isto não parece ser uma peculiaridade da diplomacia brasileira, e neste sentido, o termo paradoxo da grandeza para este aspecto poderia ser um tanto exagerado, na medida em que vários países diferenciam o atendimento consular da carreira diplomática propriamente dita. No caso brasileiro, pelo menos é possível concluir que o tardio despertar para um atendimento consular profissional à diáspora dos brasileiros seja uma manifestação do paradoxo da grandeza. Ressalvas devem ser feitas às mudanças recentes no âmbito do MRE, principalmente no seu organograma para o atendimento da comunidade de brasileiros no exterior. Estas são mudanças que caminham na direção correta. Posições recentes da diplomacia brasileira também caminham nesta direção, como é o caso da reciprocidade de tratamento no episódio que envolvia o tratamento conferido aos brasileiros que chegavam à Espanha.

\section{Melhor Prática de Gestão Migratória: o caso mexicano}

Em conversa informal com um diplomata mexicano, o mesmo disse que por muito tempo o País ignorou o problema migratório, a despeito de o fenômeno estar escancarado na cara de todo mexicano. Admitir a importância da emigração no País, segundo ele, seria o mesmo que reconhecer uma espécie de fracasso das autoridades no desenho de sua política de desenvolvimento. Era algo muito parecido com o paradoxo da grandeza acima descrito. Apenas com o reconhecimento explícito da questão migratória, principalmente a partir do Governo Fox, é que a gestão migratória mexicana deu um grande salto positivo, a ponto de virar um benchmark. A descrição do caso mexicano baseia-se no trabalho de Escobar (2008).

Se a emigração de mexicanos para os EUA é um processo antigo, a integração regional, a partir do processo NAFTA, em 1994, fez com que o processo de integração entre os dois mercados de trabalho se acelerasse substancialmente. Ao analisar políticas especialmente voltadas para a migração, Escobar (2008) lista uma série de políticas: remessas, a iniciativa “3 x 1", outros programas mexicanos para proteger migrantes, portabilidade de pensões, repatriação voluntária, diáspora, matrícula consular e organização política no exterior. 
No que tange a remessas, as mesmas representam 3,5\% do PIB mexicano, uma fração pequena (comparado com o caso brasileiro e outros casos latino-americanos), principalmente ao se considerar que cerca de $18 \%$ da força de trabalho mexicana reside nos EUA. Arazão para esta disparidade decorre do fato de que as remessas dos brasileiros apresentam um valor per capita muito maior do que a dos mexicanos. Sob o ponto de vista de políticas voltadas para remessas, a redução dos custos de transferência e o uso das matrículas consulares para abertura de contas bancárias são citadas (ESCOBAR, 2008).

A iniciativa " 3 x 1" refere-se a outro tipo de remessa. Esta iniciativa começou em Zacatecas, mas foi logo adotada em outras regiões, e baseia-se no investimento das associações comunitárias (Home Town Associations) que criaram fundos de desenvolvimento comunitários. $O$ valor destes fundos era ampliado três vezes por uma equivalência municipal, estadual e federal. Este mecanismo cresceu durante o período da administração de Vicente Fox. A despeito do sucesso do programa, este tem sido criticado, por cobrir comunidades mais ricas e por não representar investimentos produtivos (ESCOBAR, 2008).

O programa "Grupo Beta" foi criado há mais de vinte anos para proteger os mexicanos que vivem na fronteira com os EUA em relação com criminosos e abusos policiais. O "Programa Paisano" foi criado para operar antes do feriado de fim de ano, para proteger os migrantes mexicanos que vão passar o Natal com seus familiares no México (ESCOBAR, 2008).

O programa de portabilidade de pensões nunca funcionou bem, pois envolve um acordo bilateral entre o México e os EUA, mas refere-se apenas a trabalhadores que possuem o social security card legítimo, o que não representa um número significativo de pessoas (ESCOBAR, 2008).

O programa de repatriação voluntária é um programa bilateral entre o México e os EUA, que começou em 2003. O programa implica retornar o repatriado não apenas para a cidade mais próxima da fronteira mexicana, mas para o interior do México onde a pessoa reside. O objetivo é diminuir uma tentativa imediata de reentrada ilegal na fronteira (ESCOBAR, 2008).

O programa voltado para a diáspora dos mexicanos iniciou-se em 1990, quando o Ministério das Relações Exteriores lançou o "Programa para Comunidades Mexicanas no Exterior", num reconhecimento explícito de que uma comunidade permanente de mexicanos estava sendo formada nos EUA. As diásporas foram muito importantes no apoio à oposição, derrotada na 
eleição de 1988, de tal forma que o programa pode ter sido criado por razões políticas e pela crescente influência eleitoral da diáspora dos mexicanos. Em 1995, havia cerca de 400 clubes e outras organizações em cidades americanas. Muitos destes clubes eram organizados em torno de atividades sociais: por exemplo, clubes organizados em torno de times de futebol (ESCOBAR, 2008).

A matrícula consular mexicana foi precedida, no começo dos anos de 1980, por um documento para obtenção do direito de voto, uma espécie de título de eleitor, que não podia ser emitido pelos consulados. Como muitos mexicanos não possuíam documentos, os consulados mexicanos começaram a ser autorizados a emitir documentos de identificação com base nos documentos que os migrantes possuíam. O Ministério das Relações Exteriores criou, então, a matrícula consular, um documento que foi ficando popular silenciosamente e ao longo do tempo. Sua popularidade aumentou quando esta matrícula começou a ser aceita por algumas autoridades americanas: por exemplo, para emitir a carteira de motorista americana. A popularidade da matrícula consular causou reações das autoridades americanas, principalmente depois de 11 de setembro de 2001. As autoridades mexicanas reagiram criando mecanismos de segurança para a matrícula consular, tentando aumentar sua credibilidade. Amatrícula consular não era suficiente para gerar direito a voto até as eleições de 2006, constituindo uma agenda política na diáspora dos mexicanos e sua relação com a política mexicana (ESCOBAR, 2008).

A organização política dos mexicanos no exterior foi bastante incentivada no Governo Fox, com a criação do "Instituto para os Mexicanos no Exterior" (IME). O IME realizou um processo de consulta com a comunidade de mexicanos nos EUA e elegeu um conselho de cem representantes, que elegeram um representante. O IME tem também um diretor executivo oriundo do corpo diplomático, possuindo estrutura administrativa e representativa no México. O conselho opera em comissões de trabalho: educação, saúde, políticas, aspectos legais, aspectos fronteiriços, aspectos econômicos, comunicação e contato comunitário. A experiência do IME é considerada um s ESCOBAR ucesso, embora vários problemas ainda persistam. De qualquer forma, não há dúvidas de que o IME é um benchmark para qualquer país que queira experimentar avanços no atendimento à comunidade de seus nacionais vivendo no exterior (ESCOBAR, 2008). 


\section{Comentários Finais}

O presente trabalho revisou as perspectivas de gestão migratória no Brasil. As evidências são suficientes para sugerir a necessidade de uma política ativa voltada para os brasileiros residentes no exterior, assim como aqueles que pretendam fazer este movimento migratório. O paradoxo da grandeza pode ser um fator impeditivo da implementação de uma gestão migratória voltada para a diáspora dos brasileiros no exterior. De qualquer maneira, há evidências de que o MRE está caminhando para o rompimento das amarras deste paradoxo. Certamente a gestão migratória será mais efetiva se envolver várias esferas do executivo. A análise do caso mexicano como benchmark fornece várias boas práticas que poderiam ser adaptadas ao caso da diáspora dos brasileiros.

\section{Referências}

CARVALHO, José Alberto M., 1996. "O saldo dos fluxos migratórios internacionais do Brasil na década de 80 - uma tentativa de estimação", Revista Brasileira de Estudos de População, Campinas: ABEP, vol. 13, n.1, pp. 3-14, jan./jun.

CARVALHO, José Alberto M., 2004. “Migrações Internacionais do Brasil nas Duas Últimas Décadas do Século XX: Algumas Facetas de um processo complexo, amplamente desconhecido", Seminário de Migração Internacional - Ministério da Previdência Social, Brasília, julho, no prelo (forthcoming).

ESCOBAR LATAPÍ, Augustin. 2008. Mexican Policy and México-US Migration. Working Paper 167, The Center for Comparative Immigration Studies -CCIS, Universisty of California at San Diego, May 2008. 